\title{
Air leakage measurement and analysis in duct systems
}

\author{
Cigdem Aydin, Baris Ozerdem* \\ Department of Mechanical Engineering, Izmir Institute of Technology, 35430 Urla-Izmir, Turkey
}

Received 18 November 2004; received in revised form 7 May 2005; accepted 20 May 2005

\begin{abstract}
Air ducts and related equipments are used in a large number of buildings having thermal comfort. In this study, energy loss related with air leakage is studied. The leakage measurement setup was produced according to NEN-EN standards and the evaluation of data have been conducted by using power law model. The measurements were made on 300 and $1000 \mathrm{~mm}$ diameter single circular ducts, $300 \mathrm{~mm} \times 250 \mathrm{~mm}$ and $1000 \mathrm{~mm} \times 500 \mathrm{~mm}$ flanged joint rectangular ducts, 300 and $630 \mathrm{~mm}$ diameter circular beaded slip joint ducts, $300 \mathrm{~mm} \times 200 \mathrm{~mm}$ and $500 \mathrm{~mm} \times 300 \mathrm{~mm}$ rectangular flanged and drive slip joint ducts, and an branched air distribution system having different diameters for positive internal pressures. Test results have showed that the most of air leakage is from the joints. The seam contribution to air leakage is relatively lower than the joints. Using sealing gaskets help to improve the air leakage by about $50 \%$.
\end{abstract}

(C) 2005 Published by Elsevier B.V.

Keywords: Air leakage; Duct sealing; Power law model; Air distribution system

\section{Introduction}

Central heating, ventilating and air conditioning (HVAC) duct system, which is a branching networks of round and rectangular tubes made of sheet metal, fiberglass board or a flexible plastic and wire composite, includes a large variety of components such as dampers, turning vanes, variable-airvolume (VAV) control units, cooling or heating coils, supply and return registers, and sensors for temperature, humidity, smoke, carbon dioxide concentration, pressure and flow rate. HVAC equipment also contains a fan that forces acclimatized air into supply ducts leading to the rooms. Because, the purpose of HVAC duct system is to transport conditioned air between the equipment and occupied space, and to exhaust indoor air to outdoor. These air distribution systems are often used in commercial and residential buildings and sufficient care should be paid during manufacturing and installation processes. Poorly designed, constructed and installed HVAC duct systems result discomfort on occupants and excess power demand due to reduction in overall efficiency of heating and cooling equipment in buildings. Poor airtightness also contributes to the entry of outdoor pollutants.

\footnotetext{
* Corresponding author. Tel.: +90 23275065 19; fax: +90 2327506505

E-mail address: barisozerdem@iyte.edu.tr (B. Ozerdem).
}

Since an increased attention has been given to space conditioning in buildings, considerable research efforts have been done on the leakage problem of various ducts and fittings over the past years. Fisk et al. [1] have been investigated on the efficiency of air distribution systems. Their study has shown that leaking duct can reduce overall efficiency of heating and cooling systems by $20-40 \%$ in buildings. Carrie and Anderson [2] have found that the ratio between the leakage and nominal airflow rates are an average of $13 \%$ at the pressure of $50 \mathrm{~Pa}$, and $21 \%$ at the pressure of $100 \mathrm{~Pa}$, in commercial and institutional buildings. Researches done in residential and commercial buildings showed that the cooling capacity of air delivered through supply registers decreased by $10-40 \%$ due to air leakage, conduction and convection losses [3,4]. A prior research also showed that an average leakage rate in ducts was approximately $25 \%$ of the flow through the fan [5]. Heat transfer and leakage losses increase HVAC energy use even ducts are located inside the conditioned building. Franconi et al. [6] showed that when $20 \%$ of the supply air leaks from the supply ducts of a variable-air- volume (VAV) system, cooling load and fan energy increases $10 \%$ and $65 \%$, respectively. These studies indicate that the leakage rates appear greater than the maximum permitted leakage rates defined by many standards. Modera et al. [7] have been 
shown that $66-86 \%$ of the leakage in the duct systems could be sealed by aerosol injection. But further research is needed to assure that aerosol sealing does not damage duct system. In addition, further engineering is needed to develop practical technique during the sealing process. These results, once again, show that precaution should be taken at manufacturing, factory or on-site testing and installation stages.

Wyon [8] has also showed that climate control of a building strongly relates to public health and productivity concerns. According to his study, increase in productivity and decrease in health cost lie between $5 \%$ and $15 \%$ in climate-controlled buildings.

Predicting leakage has been difficult due to the lack of consistent data for contemporary duct systems and their components. This study aimed at providing duct leakage data according to standard set by European Committee for Standardization (CEN). A laboratory duct leakage measurement apparatus was developed and tests were applied to measure the total leakage rates for various cross-sectioned air ducts including their various joints and seams. Tests were performed for single and branched air distribution systems having circular and rectangular geometries. Evaluation of the data was completed by using power law model. The data were found to fit with the model. In addition to this, a review on related standards is presented.

\section{Review of the related standards}

Energy saving potential due to air leakage is on the order of $10 \mathrm{kWh} / \mathrm{m}^{2}$ per year [7]. Therefore, energy conservation concern leads the manufacturers of HVAC equipment to comply with the related standards. The standards establish the basis for duct leakage testing. According to the results of the standards, the manufacturers try to maintain leakage in the equipment within acceptable limits.

The standard set by American Society of Heating Refrigeration and Air-conditioning Engineers (ASHRAE) classifies the leakage by measuring the flow through the fan connected to duct, which was equally pressurized with the building, initially. The leakage class is defined by the equation:

$C_{\mathrm{L}}=\frac{710 F}{\Delta P^{0.65}}$

where $F$ is the leakage flow rate in $1 /\left(\mathrm{s}^{2} \mathrm{~m}^{2}\right)$, and $\Delta P$ is the pressure difference in $\mathrm{Pa}$. Leakage classes range from 3 to $12 \mathrm{cfm}$ for sealed ducts, and 30 to $48 \mathrm{cfm}$ for unsealed ducts at $250 \mathrm{~Pa}(1 \mathrm{iwg})$ per $9.3 \mathrm{~m}^{2}\left(100 \mathrm{ft}^{2}\right)$ [9].

European Committee of Air Handling and Air Conditioning Equipment Manufacturers set a standard called EUROVENT 2/2 [10]. The air ducts are classified depending on the following equation:

$K_{\text {class }}=\frac{f}{\Delta P^{0.65}}$ where $f$ is leakage factor in $\mathrm{m}^{3} /\left(\mathrm{s} \mathrm{m}^{2}\right), \Delta P$ is the pressure difference in $\mathrm{Pa}$. This standard defines three classes of airtightness: A, B and C. Test pressures for classes A and $\mathrm{B}$ are between 200 and $1000 \mathrm{~Pa}$. For class C, the test pressure can be increased to $2000 \mathrm{~Pa}$. Air tightness class values for laboratory testing are half of the installed duct testing.

Sheet Metal and Air Conditioning Contractors National Association (SMACNA) defines the leakage class as a metric to characterize the effective leakage area (ELA) [11]. It is also based on the leakage airflow rate at $250 \mathrm{~Pa}$ as ASHRAE standard. Duct leakage factor can be identified by the following relationship:

$F=C_{\mathrm{L}} P^{N}$

where $F$ is a leak rate per unit of duct surface area in $\mathrm{cfm} /$ $100 \mathrm{ft}^{2}, C_{\mathrm{L}}$ the constant, $P$ the static pressure in inches of water gage and $N$ is an exponent between 0.5 and 0.9. Seal classes are A, B and C.

DW/143 is another ductwork leakage standard prepared by Heating and Ventilating Contractors' Association (HVCA) [12]. It classifies low and medium pressure applications as A and B, respectively. Static pressure difference is between 200 and $800 \mathrm{~Pa}$ for those leakage classes. This standard defines additional leakage class called $\mathrm{D}$, besides class $\mathrm{C}$ for high-pressure level. For class $\mathrm{C}$ pressure difference is between 1200 and $1500 \mathrm{~Pa}$, whereas class D covers the region between 1500 and $2000 \mathrm{~Pa}$.

There are some other national standards that installations have to comply with, such as AS 4254 [13] in Australia, AMA 98 [14] in Sweden, DIN V 24194 [15] in Germany, ÖNORM M 7615 [16] in Austria, DS 447 [17] in Denmark, and AFNOR [18] in France.

The concern of harmonization of standards has led CEN (European Committee for Standardization) which is responsible for the planning, drafting and adoption of standards in Europe, to develop and establish new leakage standards called NEN-EN 1507 [19] and NEN- EN 12237 [20] for rectangular and circular ducts, respectively. The definition of the tightness classes has been adopted from the EUROVENT 2/2. Test static gage pressures are $400 \mathrm{~Pa}$ for class A, 400-1000 Pa for class B and 1200-1500 Pa for class C. Leakage factor, $f$, is defined as the leakage flow rate, $Q$, in $1 / \mathrm{s}$ per $\mathrm{m}^{2}$ of duct surface area, $A$, at a certain static pressure as specified in Table 1 for laboratory test.

$f=\frac{Q}{A}$

Table 1

Maximum leakage rate for laboratory test duct pressures

\begin{tabular}{llll}
\hline Static gauge $(\mathrm{Pa})$ & \multicolumn{4}{l}{ Maximum leakage $\left(1 / \mathrm{sm}^{2}\right)$} \\
\cline { 2 - 4 } & Class A & Class B & Class C \\
\hline 400 & 0.66 & 0.22 & - \\
1000 & - & 0.40 & - \\
1200 & - & - & 0.15 \\
1500 & - & - & 0.17 \\
\hline
\end{tabular}


These standards, in general, contain the basic requirements and detailed rate measuring methods and procedures for air duct systems of buildings subject to human occupancy. In the present paper, the standard set by CEN is applied during the entire study.

\section{Leakage model: power law approach}

Leakage is driven by the pressure difference. Longitudinal seams and joints are the main leakage sources through a duct envelope. Air leakage level depends on the specific geometry of the joint and seams, the sealing used, and the pressure difference between the inside and outside of the duct.

The energy conservation equation is simplified to;

$\frac{p_{1}}{\rho}+\frac{V_{1}^{2}}{2}=\frac{p_{2}}{\rho}+\frac{V_{2}^{2}}{2}+\sum$ losses

for one dimensional, steady and incompressible flow model. Here, $V_{1}$ is the leakage velocity inside the duct, $V_{2}$ the leakage velocity at the exit plane and $p_{1}$ and $p_{2}$ are the pressures at inlet and exit planes, respectively. Setting $V_{1}$ to zero and solving $V_{2}$ yields;

$V_{2}=\sqrt{2\left[\frac{p_{2}-p_{1}}{\rho}-\sum \text { losses }\right]}$

The losses depend on surface condition, flow path geometry and local Reynolds number. Some losses are proportional to the first power of the velocity, as in laminar flow, while others are proportional to the square of local velocity, as in turbulent flow. For laminar and turbulent flow losses in Eq. (6), the exit velocity is related to pressure difference by;

$V_{2}^{2}+e_{1} V_{2}+e_{\mathrm{t}} V_{2}^{2}=2\left[\frac{p_{1}-p_{2}}{\rho}\right]$

where $e_{1}$ is sum of the laminar loss coefficients, and $e_{\mathrm{t}}$ is sum of the turbulent loss coefficients. Eq. (7) shows that the leakage velocity is proportional to the $n$th power of the pressure differential.

Application of the continuity equation leads to;

$Q=\int_{A} V_{\text {ave }} \mathrm{d} A=\sum_{i=1}^{m} V_{i} A_{i}$

Since $Q$ is proportional to $V$, by using $c$ as proportionality constant, the leakage flow rate through a leakage area $A$ is given by;

$Q=c A(\Delta p)^{n}$

In order to preserve the form of above equation, the normalized pressure difference, $\Delta p_{\text {norm }}$, is described as;

$\Delta p_{\text {norm }}=\frac{\Delta p}{\Delta p_{\text {ref }}}$ where $\Delta p_{\text {ref }}$ is reference pressure difference of $250 \mathrm{~Pa}$, whereas $\Delta p$ is any pressure difference in $\mathrm{Pa}$. Because, it is needed to combine the unknown coefficient and leakage area and express normalized pressure difference [21].

Therefore, Eq. (9) can be rewritten as;

$Q=C\left(\Delta p_{\text {norm }}\right)^{n}$

Eq. (11), called the power law model, was used to relate leakage rate data to the pressure difference driving the leakage. The power law leakage model provides a convenient method by which to predict the leakage of a duct system when reliable values for $C$ and $n$ are available.

\section{Test setup and procedure}

The leakage rates for air distribution duct systems were determined by measuring the makeup air required to maintain the duct system at a constant pressure. The duct pressure and the makeup flow rate were measured over a range of pressures between 400 and $1500 \mathrm{~Pa}$. The leakage measurement setup was produced according to NEN-EN standards as shown in Fig. 1. The system had a radial fan with variable speed control to supply makeup air. The output of the fan was manifolded into $200 \mathrm{~mm}$ diameter pipe with an adaptor piece. The variable speed control unit was used to obtain a fine adjustment of airflow into the test setup. The straightener was used to get laminar flow on cross-section area of measured air velocity. The digital anemometer was connected to the test setup and used to measure the makeup airflow. The anemometer size was selected for the flow rate range needed for a test. The manometer was used to measure the pressure drop through the test duct. The test setup was completely sealed to ensure that leakage at the end caps and connecting pipe was at ignorable level.

Tested ducts and their various dimensions are shown in Table 2. Spiral lock seam was used for circular duct, whereas Pittsburgh lock seam was used for rectangular duct. The leakage rates for individual sites were determined by measuring leakage with and without sealing. For example, the seam leakage was determined by measuring the leakage with sealed joints. In order to measure the joint leakage, similar sealing process was applied to the seam. Spiral lock seam ducts were produced at 1 and $1.25 \mathrm{~m}$ lengths. Pittsburgh lock seam ducts were produced at $1.2 \mathrm{~m}$ lengths

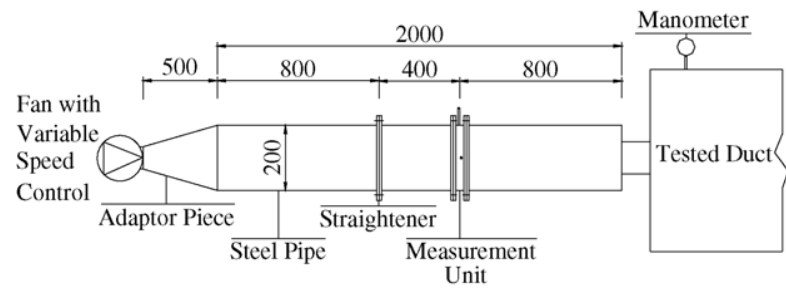

Fig. 1. The leakage measurement setup. 
Table 2

Physicals characteristics for test ducts

\begin{tabular}{|c|c|c|c|c|}
\hline Duct type & Dimensions (mm) & Thickness (mm) & Length (m) & Surface area $\left(\mathrm{m}^{2}\right)$ \\
\hline \multirow[t]{2}{*}{ Circular single ducts } & $\varnothing 300$ & 0.65 & 5 & 4.71 \\
\hline & $\varnothing 1000$ & 1.05 & 5 & 15.70 \\
\hline \multirow[t]{2}{*}{ Rectangular flanged joint ducts } & $300 \times 250$ & 0.55 & 4.8 & 5.28 \\
\hline & $1000 \times 500$ & 0.75 & 4.8 & 14.4 \\
\hline \multirow[t]{2}{*}{ Circular beaded slip joint ducts } & $\varnothing 300$ & 0.65 & 5 & 4.71 \\
\hline & $\varnothing 630$ & 0.85 & 4 & 7.92 \\
\hline \multirow[t]{2}{*}{ Rectangular flanged and drive slip joint ducts } & $300 \times 200$ & 0.55 & 4.8 & 4.8 \\
\hline & $500 \times 300$ & 0.55 & 4.8 & 7.68 \\
\hline Branched air distribution system & $150-280$ & $0.55-0.75$ & 8.5 & 7.14 \\
\hline
\end{tabular}

and connected to each other with flange and gasket. Pittsburgh lock and spiral lock seam duct were suspened at three points. The muff was welded on the duct for the assembly of the manometer.

Geometry of joints on rectangular ducts were chosen flanged joint with gasket and drive slip joint. Geometry of joints on circular ducts were chosen beaded slip coupler with two different gaskets such as single sided and double sided seals (Fig. 2). Three different test systems were used: circular ducts in 1-1.25 m sections, rectangular ducts in $1.2 \mathrm{~m}$ sections and branched air distribution system with circular ducts in different diameters. Figs. 3-5 show the test systems for single circular, rectangular and branched air distribution ducts, respectively.

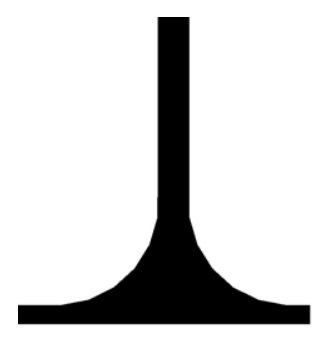

(a)

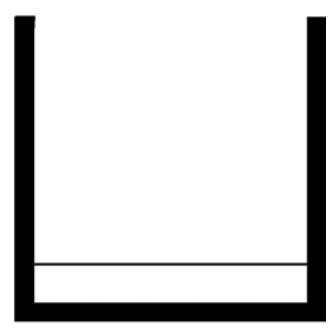

(b)
Fig. 2. Sealing gasket profiles: (a) single sided, (b) double sided.

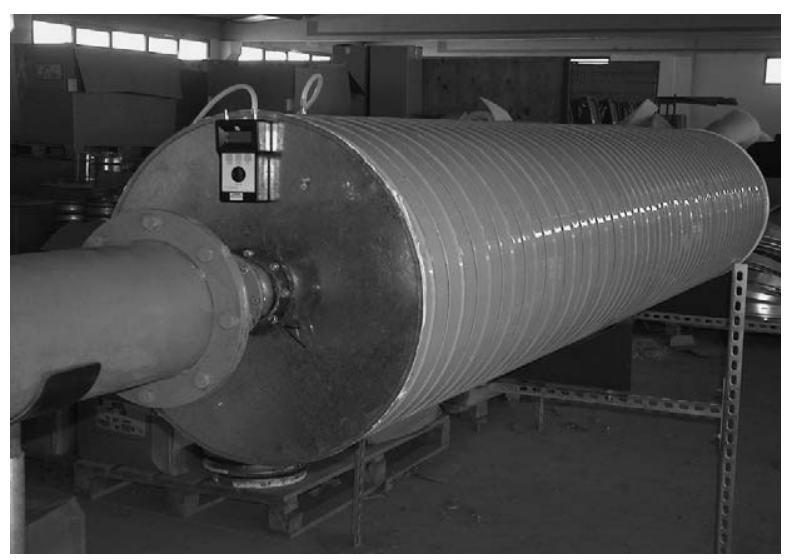

Fig. 3. Single circular duct test system.
Firstly, the duct was connected to the test setup. Then, the fan was run during 15 min without any data saved to get stable airflow at required test pressure. The test pressure was adjusted with variable speed control unit. All leakage measurement was made by increasing the internal pressure in the test system in several steps from 400, 1000 and $1200 \mathrm{~Pa}$ to the maximum pressure of $1500 \mathrm{~Pa}$. These settings were controlled with the manometer on the tested duct.

Digital anemometer on the leakage measurement system, 2D-lengths away from the straightener, was used for measuring air velocity. Any measured velocity value for

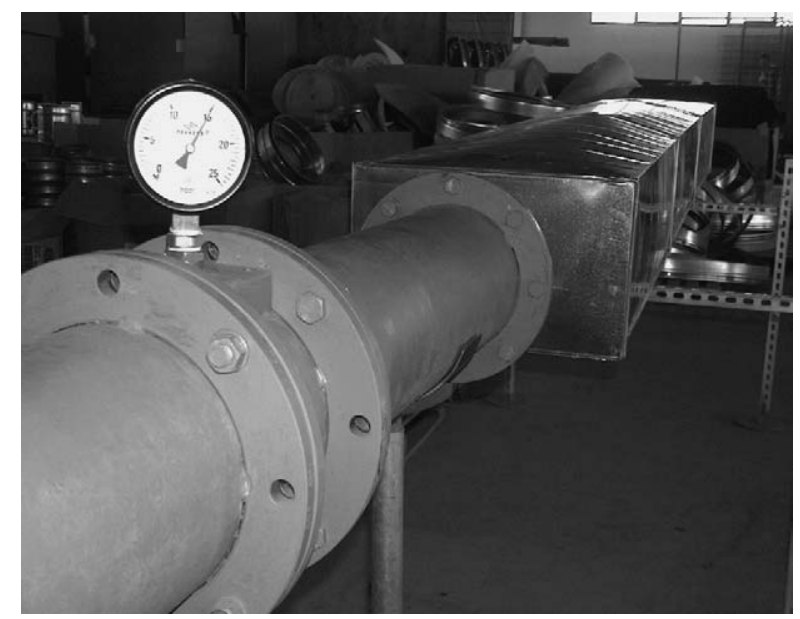

Fig. 4. Rectangular duct test system.

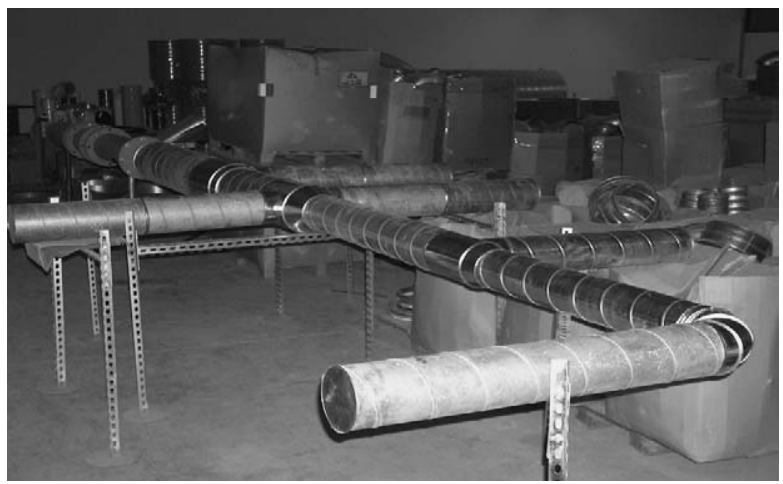

Fig. 5. Branched air distribution system in different diameters. 


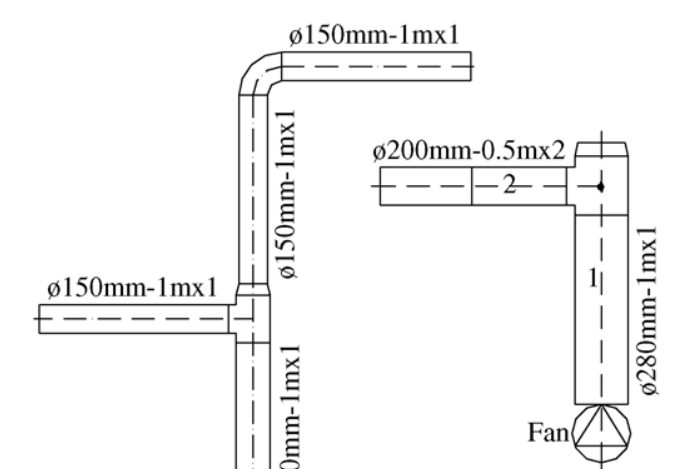

(a) $1 \mathrm{j} 2$ Site

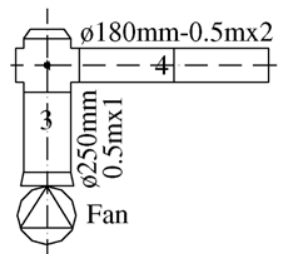

(b) $3 \mathrm{j} 4$ Site

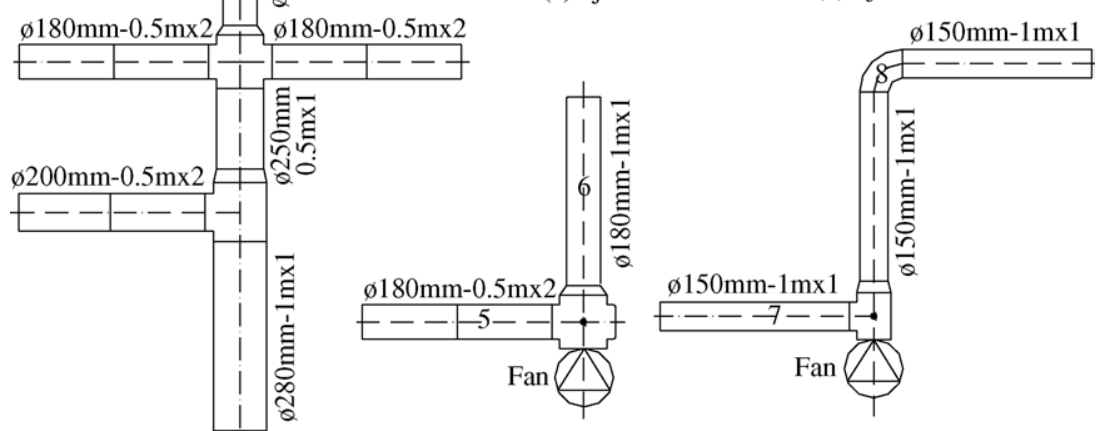

$\begin{array}{ll}\text { (c) } 5 \mathrm{j} 6 \text { Site } & \text { (d) } 7 \mathrm{j} 8 \text { Site }\end{array}$

Fig. 6. Schematic view and sites for air distribution system.

each point was resulted from air leakage through the tested duct. For each test pressure, the air velocity was measured at eleven points both on horizontal and vertical axis.

Branched air distribution system in different diameters was divided into four individual sites named $1 \mathrm{j} 2,3 \mathrm{j} 4,5 \mathrm{j} 6$ and $7 \mathrm{j} 8$ as shown in Fig. 6. All leakage measurements were made for five different sets including total system.

\section{Test results}

\subsection{Test results for single circular and rectangular flanged joint ducts}

Leakage factors for single circular and rectangular flanged joint ducts, which have the same seam lengths are

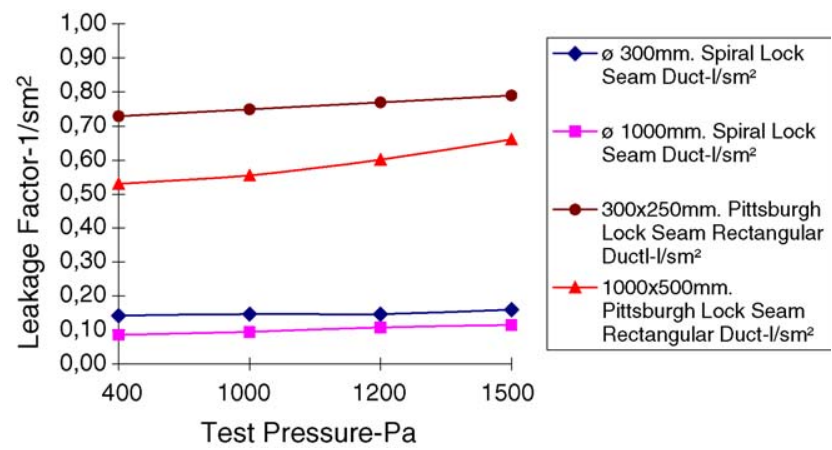

Fig. 7. Leakage factors vs. test pressures for single circular and rectangular ducts having the same seam lengths. shown in Fig. 7 at different test pressures. The air leakage from duct, with the same lock seam type, decreases whereas the surface area increases. It is found that, the air leakage from a circular duct is approximately $80 \%$ less than a rectangular duct for the same seam length.

\subsection{Test results for circular beaded slip joint ducts}

Leakage rates for unsealed circular beaded slip ducts in 300 and $630 \mathrm{~mm}$ diameters are shown in Figs. 8 and 9, respectively. It is seen in Fig. 8 that, joint leakage ratio is $95 \%$ of total leakage whereas, the seam leakage ratio is $5 \%$ of total leakage.

Fig. 9 shows that, joint leakage ratio is $97 \%$ of total leakage whereas, the seam leakage factor is $3 \%$ of total leakage.

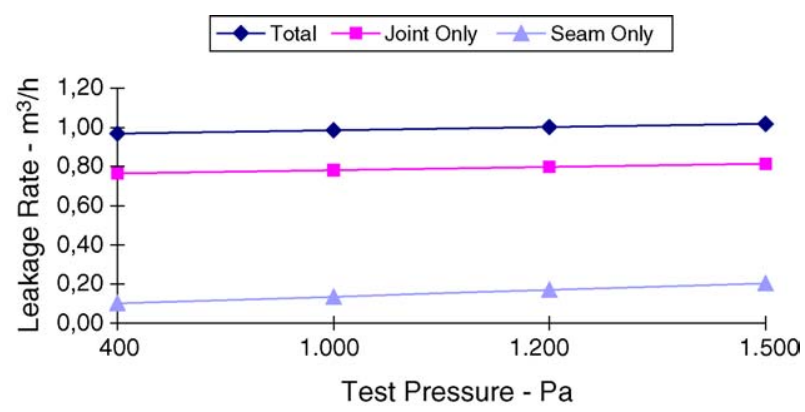

Fig. 8. Leakage rates on spiral lock seam with beaded slip joint circular duct (Ø $300 \mathrm{~mm}$ ). 


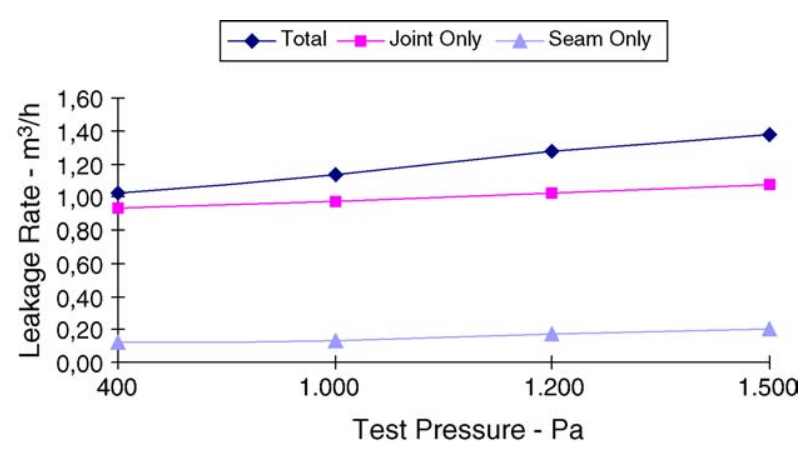

Fig. 9. Leakage rates on spiral lock seam with beaded slip joint circular duct (Ø $630 \mathrm{~mm})$.

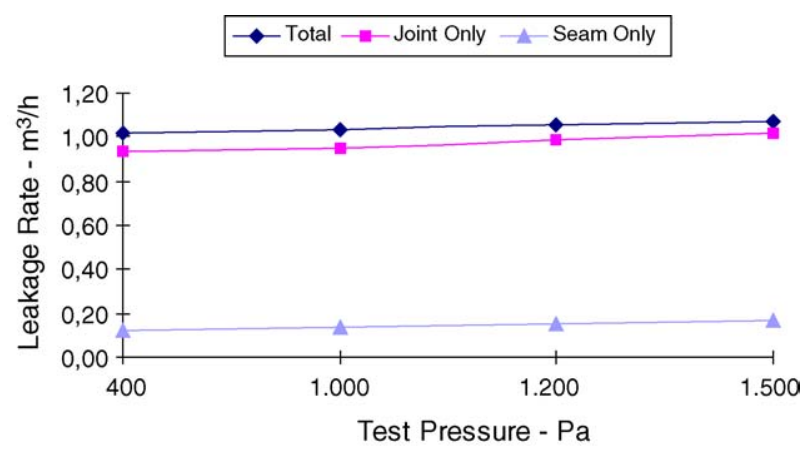

Fig. 10. Leakage rates on flanged joint rectangular duct $(300 \mathrm{~mm} \times$ $200 \mathrm{~mm})$.

Similar tests were performed for sealed systems with single and double sided gaskets. Comparison of the results is given in Table 3.

\subsection{Test results for rectangular flanged and drive slip joint ducts}

Leakage rates for rectangular flanged joint ducts in $300 \mathrm{~mm} \times 200 \mathrm{~mm}$ and $500 \mathrm{~mm} \times 300 \mathrm{~mm}$ dimensions are shown in Figs. 10 and 11, respectively. It is seen in Fig. 10 that, joint and corner leakage ratio is $86 \%$ of total leakage whereas, the seam leakage ratio is $14 \%$ of total leakage.

Fig. 11 shows that, joint and corner leakage ratio is $80 \%$ whereas, the seam leakage factor is $20 \%$ of total leakage. Comparison between flanged and slip joint rectangular ducts is given in Table 4.

Table 3

Comparison of test results for circular beaded slip joint ducts

\begin{tabular}{llll}
\hline Duct size $(\mathrm{mm})$ & $\begin{array}{l}\text { Double sided } \\
\text { sealing gasket }\end{array}$ & $\begin{array}{l}\text { Single sided } \\
\text { sealing gasket }\end{array}$ & $\begin{array}{l}\text { Unsealed } \\
\text { system }\end{array}$ \\
\cline { 2 - 4 } & $\begin{array}{l}\text { Joint by } \\
\text { total }(\%)\end{array}$ & $\begin{array}{l}\text { Joint by } \\
\text { total }(\%)\end{array}$ & $\begin{array}{l}\text { Joint by } \\
\text { total }(\%)\end{array}$ \\
\hline$\varnothing 300$ & 89 & 92 & 95 \\
$\varnothing 630$ & 92 & 95 & 97 \\
\hline
\end{tabular}

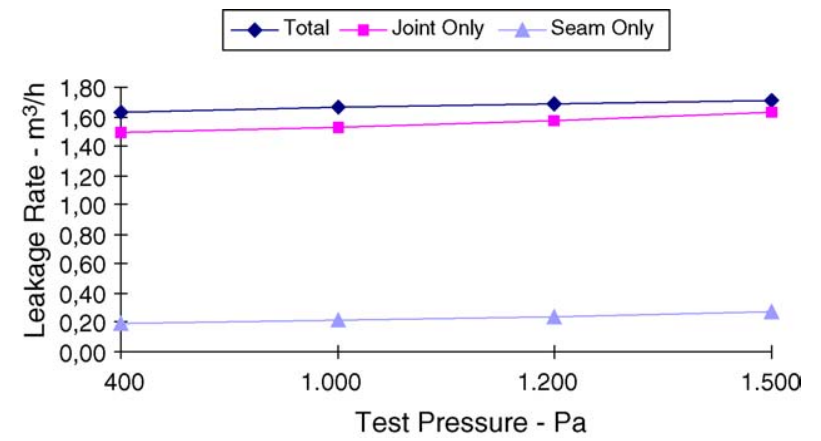

Fig. 11. Leakage rates on flanged joint rectangular duct $(500 \mathrm{~mm} \times$ $300 \mathrm{~mm})$.

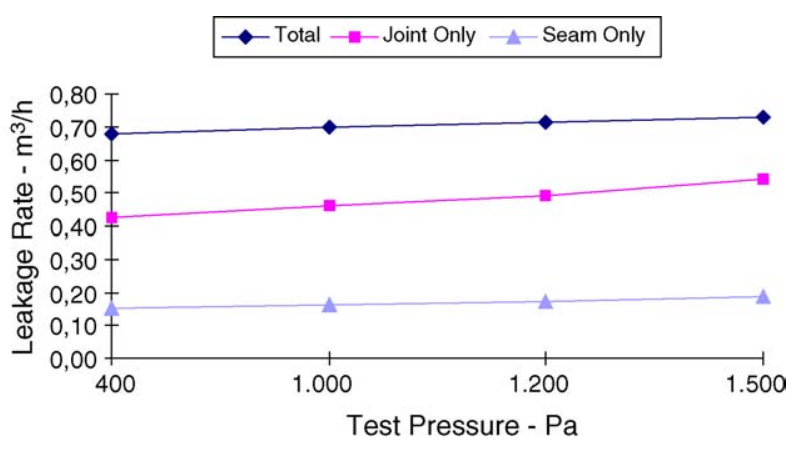

Fig. 12. Leakage rates on unsealed branched air distribution system having different diameters.

\subsection{Test results for branched air distribution duct system}

Leakage rates for unsealed branched air distribution duct system at different test pressures are shown in Fig. 12 including total, joint and seam leakages. It is seen in Fig. 12 that, joint leakage ratio is $78 \%$, whereas the seam leakage factor is $22 \%$ of total leakage. Similar tests were also performed for systems having single and double-sided sealing gaskets. Analysis of the data showed that the power law model was fitted quite good. The method of least squares is used to obtain the best-fit average values of $C$ and $n$. These average values are listed for unsealed and sealed cases in Table 5. It should be noted that sealed system leaks less than unsealed one by about $50 \%$. The air flow, in sealed system, is also more steady than unsealed system.

Table 4

Air leakage comparison between flanged and slip joint rectangular ducts

\begin{tabular}{lll}
\hline Duct size $(\mathrm{mm})$ & Flanged system & Drive slip system \\
\cline { 2 - 3 } & Joint by total $(\%)$ & Joint by total $(\%)$ \\
\hline $300 \times 250$ & 65 & 86 \\
$500 \times 300$ & 60 & 80 \\
\hline
\end{tabular}


Table 5

Comparison between unsealed and sealed branched air distribution systems with single or double sided sealing gaskets

\begin{tabular}{lll}
\hline Type & $\begin{array}{l}\text { Flow coefficient } \\
C\left(\mathrm{~m}^{3} / \mathrm{h}\right)\end{array}$ & $\begin{array}{l}\text { Flow } \\
\text { exponent } n\end{array}$ \\
\hline $\begin{array}{c}\text { Double sided sealing } \\
\text { gasket system }\end{array}$ & 2.67 & 0.66 \\
$\begin{array}{c}\text { Single sided sealing } \\
\text { gasket system }\end{array}$ & 2.82 & 0.58 \\
Unsealed system & 4.11 & 0.32 \\
\hline
\end{tabular}

\section{Conclusions}

In the present study, a laboratory scale duct leakage measurement apparatus was developed and leakage tests for various cross-sectioned air ducts were performed according to NEN-EN standards. Measured data showed that power law model is in good agrement for tested ducts.In this study, the leakage characteristics of eleven different duct types were evaluated. The results of the measurements are shown that the largest portion of total leakage occurs at joint surfaces and corners. These values can go up to $92 \%$ for circular and $86 \%$ for rectangular ducts. On the other hand, the largest seam leakage can reach up to $13 \%$ for circular and $20 \%$ for rectangular ducts. These data also showed that spiral lock seam has lower leakage rate than Pittsburgh lock seam. Sealing was found to be effective in reducing duct leakage. Air leakage through the duct reduces the performance of HVAC systems. Therefore, an additional leakage class should be introduced for laboratory tests (e.g. class D). Because, air thightness values were better than the best class (which is class C) in NEN-EN standards for all cases of this study. If air leakage exceeds a certain amount, ventilation device characteristics should be reconsidered. Because fan power is cubic function of flow rate. So, lowering flow rate causes saving in fan energy use. Proper installation and avoiding or reducing leakage will also increase the comfort and effectiveness level, especially, in terms of contaminant removal from a room. Poor performances are result of not using factory-fitted sealing gaskets. In most cases, duct system installations are done by using in situ sealing techniques such as mastic application or taping. Using factory-fitted component means additional cost. But saving on energy and labour cost can effect Life Cycle Cost of the duct system, positively. Finally, since duct leakage is a very active field of study, further examinations are needed on the issue.

\section{Acknowledgements}

We, authors, acknowledge with thank the company Venco A.S. for their assistance in construction of the setup and the ducts used in this study.

\section{References}

[1] W.J. Fisk, W.W. Delp, R. Diamond, Duct systems in large commercial buildings: physical characterization, air leakage, and heat conduction gain, Energy and Buildings 32 (2000) 109-119.

[2] F.R. Carrie, J. Anderson, Improving ductwork, Energy in Buildings and Community Systems Program (2000).

[3] F.R. Carrie, A. Bossaer, J.V. Andersson, P. Wouters, M.W. Liddament, Duct leakage in European buildings: status and perspectives, Energy and Buildings 32 (2000) 235-243.

[4] W.W. Delp, J. McWilliams, D.J. Dickerhoff, D. Wang, M.P. Modera, Thermal Distribution Losses in Light Commercial Buildings LBNL-42415, Lawrence Berkeley National Laboratory, Berkeley, CA, 1998.

[5] R. Levinson, W. Delp, D. Dickerhoff, W. Fish, M. Nematollahi, I. Stordahl, C. Torre, D. Wang, R. Diamond, M. Modera, Commercial Thermal Distribution Systems: Final Report for California Institute for Energy Efficiency, LBNL-41045, Lawrence Berkeley National Laboratory, Berkeley, CA, 1997.

[6] E. Franconi, W.W. Delp, M.P. Modera, Impact of duct air leakage on VAV system energy use LBNL-42417, Lawrence Berkeley National Laboratory, Berkeley, 1998.

[7] M.P. Modera, O. Brzozowski, F.R. Carrie, D.J. Dickerhoff, W.W. Delp, W.J. Fisk, R. Levinson, D. Wang, Sealing ducts in large commercial buildings with aerosolized sealant particles, Energy and Buildings 34 (2002) 705-714.

[8] D.P. Wyon, Healty buildings and their impact on productivity, in: Proceedings of Indoor Air Conference, Helsinki, Finland, 1993, pp. $3-$ 13.

[9] ASHRAE Handbook: Fundamentals, American Society of Heating, Refrigeration, and Air Conditioning Engineers Inc. Atlanta, 1997.

[10] EUROVENT 2/2, Air leakage rate in sheet metal air distribution in: Eurovent/Cecomaf, 1996.

[11] SMACNA, HVAC air duct leakage test manual, Sheet Metal and Air Conditioning Contractors National Association Inc. Chantilly, 1985.

[12] HVCA, DW 143, A practical guide to ductwork leakage testing, Heating and Ventilating Contractor's Association, London, 1994.

[13] AIRAH, Duct Design Manual, Australian Institute of Refrigeration, Air-Conditioning and Heating, Melbourne, 1980.

[14] VVS AMA 98, Allmän material-och arbeitsbesk rivning för VVStekniska arbeten, AB Svensk Byggtjänst, Stockholm, 1998.

[15] DIN V24194, Kanalbauteile für lufttechnische Anlagen, Dichtheit. Dichtheitsklassen von Luftkanal System, 1995.

[16] ÖNORM M 7615, Code of Practice of Ventilation Installations. Dansk Ingeniorforening, 1981.

[17] DS 447 Code of Practice of Ventilation Installations. Dansk Ingeniorforening, 1981.

[18] AFNOR, Degrédétanchéité á l'air dans les réseaux de disribution d' air en tole. Norme no NF X 10-236.

[19] NEN-EN 1507, Ventilatie van gebouwen. Luchtleidingen Rechthoekige dunwandige metalen luchtleidingen. Sterkte en lekkage. Eisen en beproevingen September 1994.

[20] NEN-EN 12237, Ventilatie van gebouwen. Luchtleidingen. Ronde dunwandige metalen luchtleidingen. Sterkte en lekkage. Eisen en beproevingen December 1995.

[21] W.B. Swim, E.I. Griggs, Duct leakage: Measurement, analysis and prediction models. ASHRAE Research project 447, Atlanta, ASHRAE Inc., 1989. 